Modern Physics Letters A, Vol. 9, No. 9 (1993) 861

(C) World Scientific Publishing Company

\title{
ERRATUM
}

\section{ON THE DEFINITENESS OF THE CONFORMAL ANOMALY IN NONCONFORMAL GAUGES}

\author{
[Mod. Phys. Lett. A, Vol. 9, No. 3 (1994) 241-245] \\ W. Mödritsch
}

On p. 245

In the Note Added section, the numbers (9) and (10) in the second line should read (18) and (19). 